\title{
Tarihi Eserlerin İnsansız Hava Aracı İle Modellenmesinde Karşılaşılan Sorunlar
}

\author{
Murat YAKAR ${ }^{1 *}$ Ömer Mirdan ${ }^{1}$ \\ ${ }^{1}$ Mersin Üniversitesi, Mühendislik Fakültesi, Harita Mühendisliği Bölümü, Mersin \\ (myakar, omirdan@mersin.edu.tr) ORCID ID 0000-0002-2664-6251, ORCID ID 0000-0002-2456-1270
}

Öz

Tarih boyunca, Türkiye farklı kültürlere ve inanışlara sahip medeniyetlere ev sahipliği yapmıştır. Bundan dolayı ülkenin birçok yerinde bu medeniyetlerden kalan kültürel mirasları görmek mümkündür. Geçmişten günümüze sşı tutan bu eserler insani veya doğal nedenlerden dolayı ya yok olmakta ya da çok büyük hasarlara uğramaktadır. Birçok tarihi yapı ve kültürel miras doğal olaylar ve insan aktiviteleri nedeniyle zarar görmüş̧ür. $\mathrm{Bu}$ eserlerin dokümantasyonu, korunması ve tanıtılması amacıyla üç boyutlu modellerinin üretilmesi için farklı yöntemler kullanılmaktadır.

Fotogrametri, tarihi yapıların ve kültürel mirasın dokümantasyonu ve üç boyutlu modellerinin üretimi için kullanılmaktadır. İHA'lar (İnsansız Hava Araçları) üzerinde insan bulunmadan uçabilen ve uzaktan kontrol edilen sistemler olarak tanımlanır. Gelişen teknoloji ile birlikte İHA'lar Fotogrametri Teknikler ile birlikte kullanılmaya başlanmış ve 3B modellemeye yeni bir ivme kazandırmıştır. Günümüzde üç boyutlu modeller eğitimden turizme kadar birçok farklı alanda kullanılmaktadır. Bu nedenle eserlerin korunması, gerektiğinde yeniden inşa edilmesi ve gelecek nesillere aktarılması için hızlı bir şekilde belgelenmesi gerekmektedir.

Anahtar Kelimeler: Fotogrametri, Yersel Fotogrametri, Kültürel Miras, Insansız Hava Aracı.

\section{Compared Problems At Modeling Of Cultural Heritages With Unmanned Aerial Vehicles}

\begin{abstract}
Throughout the history, Turkey has hosted several civilizations which have different cultures and beliefs. Therefore, it is possible to see cultural heritages that were inherited from these civilizations at several places in the country. These artifacts, which shed light from past to present, are destroyed or substantially damaged because of human activity and natural disasters. Most of the historical buildings and cultural heritages are damaged according to human activities or natural events. Different methods are used in order to be documented, protected and introduced of these monuments. Photogrammetry is used, to 3D modeling of historical monuments and cultural heritages and for their documentation. UAVs (Unmanned air vehicle) are vehicles which can fly without a pilot and can be remote controlled with the innovations and developments in technologies, UAV's start to be used in 3D modeling on photogrammetric techniques. In today life,3D models are widely ranges from tourism to education; it can be almost one very field. These precious artifacts are required to be documented as soon as possible for protection and reconstruction projects in order to transmit the artifact to future generations. Because the traditional methods are slow and having low acquisition, advanced technologies are necessary for documentation of cultural heritages. Terrestrial laser scanning technology, is one of these advanced technologies, allows measuring of cultural heritages rapidly, accurately and in detail. Also, these technologies enable users to document, digitally achieve and construct 3D model of cultural heritage.
\end{abstract}

Keywords: Terrestrial Photogrammetry, Cultural Heritage, Unmanned Aerial Vehicle, Terrestrial Laser Scanning.

* Sorumlu Yazar 


\section{GİRIŞ}

Günümüzde klasik bilgisayar tabanlı $3 \mathrm{~B}$ modelleme tekniklerinin yanı sıra fotogrametrik ve mesafe ölçme tabanl teknikler 3B modelleme çalışmalarında kullanılmaktadır. Fotogrametrik ve mesafe ölçme tabanlı ölçme sistemleri gerçek obje geometrisinin belirlenmesinin yanında objenin coğrafi referansı ile birlikte modellenmesi imkânı sağlamaktadır. Ayrıca bu teknolojiler özellikle objenin gerçek görüntüsü ile beraber alım yaptıkları için gerçek görüntünün doku olarak modellere geçirilmesi konusunda artı olanaklar sağlamaktadır.

$\mathrm{Bu}$ bağlamda fotogrametri özellikle yeni gelişen görüntü işleme teknikleri ile hem Yersel hem de İnsansız Hava Aracı (IHHA) bazlı uygulamaları ile Mimari, Arkeolojik ve Tarihi eserler 3B modelleme çalışmalarının gözdesi haline gelmiştir. Son yıllarda yersel Fotogrametri ve Bilgisayar teknolojisindeki gelişmeler sonucu binaların 3 boyutlu olarak tekrar oluşturulması güncel araştırma konuları içinde yer almıştır. (ASRİ 2014)

$\mathrm{Bu}$ çalışma ile Kalender Baba ve Kesik Baş Türbesi fotogrametrik olarak ölçülmesi, 3B modellenmesi ve gerçek dokuları ile kaplanması amaçlanmıştır. $\mathrm{Bu}$ çalışmada ölçümler, 4 adet poligon noktası yardımıyla yapıyı içine alacak şekilde kapalı poligon geçkisi tesis etmek suretiyle Topcon GPT 3007 Reflektörsüz Total Station cihazı yardımıyla gerçekleştirilmiştir. Doku kaplaması ve Çizim işlemlerinde, Yapının Yüksek olmasının yarattı̆g dezavantaj1 giderebilmek için Fotoğraf çekimleri için İHA' ya entegre Canon A810 Dijital Fotoğraf Makinası ile çatı ve cephe çekimleri şeklinde gerçekleştirilmiştir. Photomodeler Programı yardımıla yapının üç boyutlu modeli elde edilmiştir.

\section{MATERYAL VE METOT}

\section{1. İnsansız Hava Araçları (İHA)}

Günümüzde insansız hava araçlarının (İHA) gelişen teknoloji ile birlikte hızla gelişmesi beraberinde bu araçların kullanım yelpazesini oldukça genişletmiş ve çok farklı meslek disiplinlerinde yerini almıştır. $\mathrm{Bu}$ meslek disiplinleri arasında başta askeri uygulamalar olmak üzere, jeolojik ve meteorolojik araştırmalar, doğal afet yönetimi, uluslararası sinır devriyesi, orman yangını tespiti, deformasyon analizi, yeryüzünün haritalanması ve 3 boyutlu şehir veya arazi modelleme gibi kullanım alanları yer almaktadır. Bu tür araçların kullanımı harita mühendisliği dalında da önemli ölçüde yer etmiştir. İHA'lar yerleştirilen Dijital kamera ve diğer navigasyon sistemleri sayesinde insanların erişmekte zorlandı ̆̆ı ya da imkânsız olduğu yerlerde ölçüm yapabiliyor olması ve sağladığı verilerin ölçüm hassasiyeti bakımından klasik yöntemlere yaklaşmasından dolayı bu ölçme sisteminin yersel ölçme yöntemi ile Klasik Hava Fotogrametrisi arasinı doldurmaya aday olduğu görülmektedir.

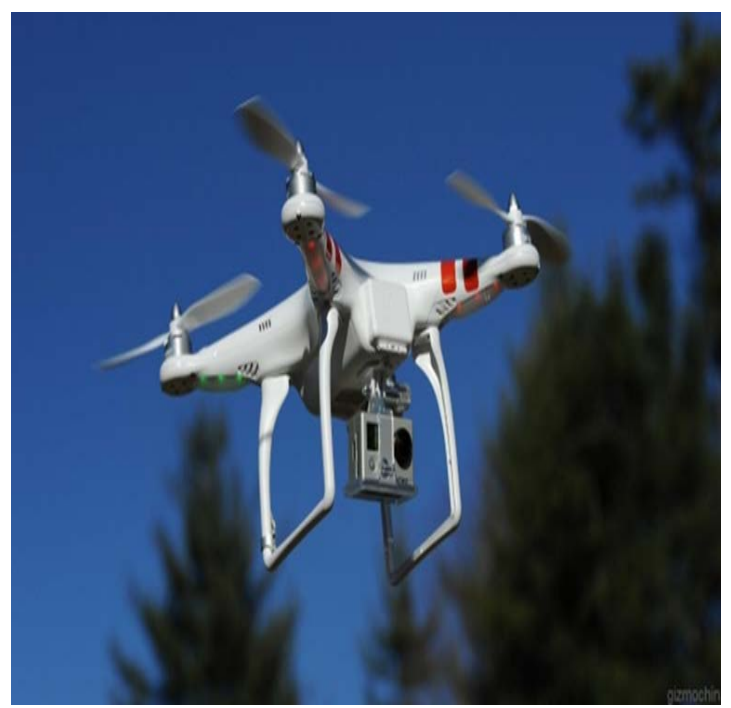

Şekil 1. İnsansız hava aracı

Insansız Hava Araçları'ları Kullanmanın Avantajlart

İHA'ların klasik sistemlerden avantajl1 yönlerinden bazıları aşağıda sıralanmıştır.

- İHA'ların hayati tehlike ve diğer risk potansiyeli olan uygulama alanlarında kullanılabilmesidir. $\mathrm{Bu}$ tür riskli durumlara örnek olarak nükleer santraller, kimya depolama alanları yanardağ bölgeleri, deprem bölgeleri, sel vb. felaketler olmuş bölgeler gibi uygulama alanları sayılabilir.

- İHA'ların kullanımının oldukça pratik olmasidir. 
- Bulutlu havalarda klasik fotogrametri ve uzaktan algılama sistemlerinden daha sağliklı sonuçlar verebilmektedir.

- Klasik hava fotogrametrisinde ya da uzaktan algılama sistemlerinde istenilen verilerin büro çalışmasından sonra elde edilirken bu durum İHA'lar için daha hızlı bir biçimde hatta eşzamanlı olarak veriler elde edilebilmektedir. - Klasik yöntemlere göre genel olarak daha düşük bir maliyetle işlerin yapılabilmesi, ancak daha önceden de bahsedildiği gibi uygulamanın türüne ve kullanılan teknolojinin çeşitliliğine ve türüne bağlı olarak maliyet değişebilmektedir.

- 3Boyutlu model ve sayısal yüzey modelleri için yüksek çözünürlüklü doku haritaları içinde kullanılabilmektedir. Özellikle kopterler (geleneksel helikopter, quadro, hexa veya octakopter) dikey olarak havalanabildikleri ve havada as1l durabildikleri için taşıdıkları kameraları düşey ve yatay olarak hareket ettirebildiklerinden havada sabit noktadan resim alabilmektedirler. Bu özelliği ile 3Boyutlu model oluşturma ya da özel incelemelerde rahatlıkla kullanılabilmektedir.

- Sivil Havacılık Genel Müdürlüğü tarafından İHA'lar için belirlediği limitlerin altında ki araçlar için izin alma zorunluluğunun olmaması. Bu limitler şu şekildedir, izinsiz uçuş için:

- İHA’nın 4 kg'ın altında ağırlığa sahip olması

- Hizının 50 km/Saat'in altında olması

- Manüel kullanımında olmasi

-100 m'nin altında bir yükseklikte uçurulması

\section{Insansız Hava Araçlarının kullanım alanları}

İHA tehlikeli ya da geçici olarak ulaşılmaz yerlerde çalışabilir. İHA da bir durumun hem hızlı bir bakış hem de ayrıntılı alan belgeler sağlayabilir. Ancak, önce başarılı bir İHA operasyonu, geniş bir görev planlama gereklidir.

Arazi, orto görüntülerinin ve İHA görüntü veya diğer algılayıcı verilerinden dokulu 3D model çıkarma, tehlikeler ya da çevre felaketleri, bina çökmesi, uçak kazaları, arama ve kurtarma operasyonları, yangın ile mücadele, bitki zarar, heyelan ve volkan patlaması ve acil müdahale yöntemleri gibi sikıntılı durumlarda olayları koordine etmek amaciyla kullanılabilir. Diğer uygulama alanları kültürel mirası, enerji hatları, boru hatt1 denetim, baraj izleme ve kadastro verilerinin kayıt ölçme çalışmaları gibi uygulamaları içerir.

Genel olarak, günümüzde İnsansız Hava Araçları sistemleri aşağıda belirtilen konularda kullanılmaktadır

- $\quad$ Havadan haritalama hizmetleri

- $\quad$ Havadan arama ve kurtarma

- $\quad$ Hava gözetim hizmetleri

- Hava güvenlik hizmetleri

- Havadan Araştırma Hizmetleri

- $\quad$ Hava fotoğrafçıllı̆ 1

- $\quad$ Havadan video çekimi

- Bilimsel araştırma uygulamaları

\subsection{UYGULAMA}

Kalender baba, Kesikbaş Türbesinin 3B modellenmeleri için İnsansız Hava Aracı yöntemi kullanılmıştır.

$\mathrm{Bu}$ uygulamada, çalışma öncesi hazırlık ve arazi çalışması ve ofis çalışması olmak üzere üç aşamadan oluşmaktadır. Arazi çalıșması bir gün sürmüştür ve ofis çalışması ise 3 gün sürmüştür.

\subsection{1. Çalışma öncesi hazırlık}

Bu kısım çalışmada havadan fotoğraf çekmek için İnsansız Hava Aracı (IHA) temin edilmiştir. Daha sonra resim çekimleri için dijital kamera temin edilmiştir. Ayrıca temin edilmiş fotoğraf makinesi İnsansız Hava Aracına entegre edilmiştir. Daha sonra yer ve yapı kontrol levhaları da plakalar şeklinde hazırlanmıştır. 

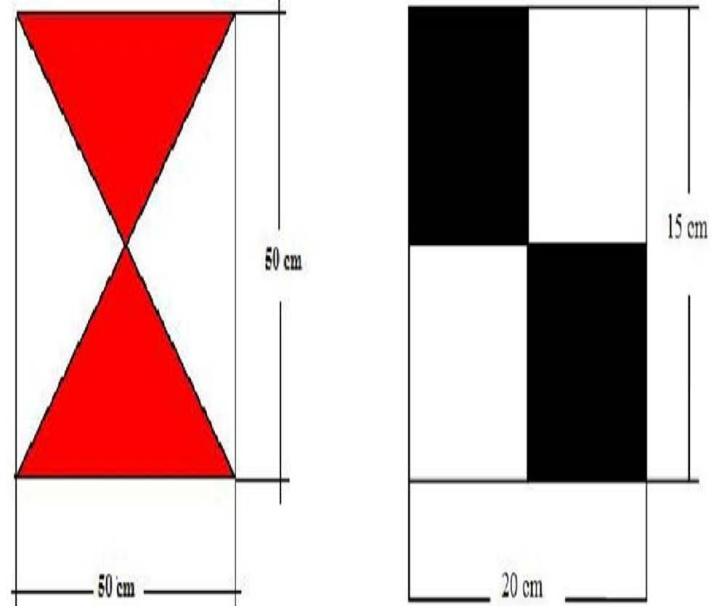

Şekil 2. Havadan çekilen fotoğraflarda kullanılan yer (sol) ve yap1 (sağ) kontrol noktalarının yakından görünümü
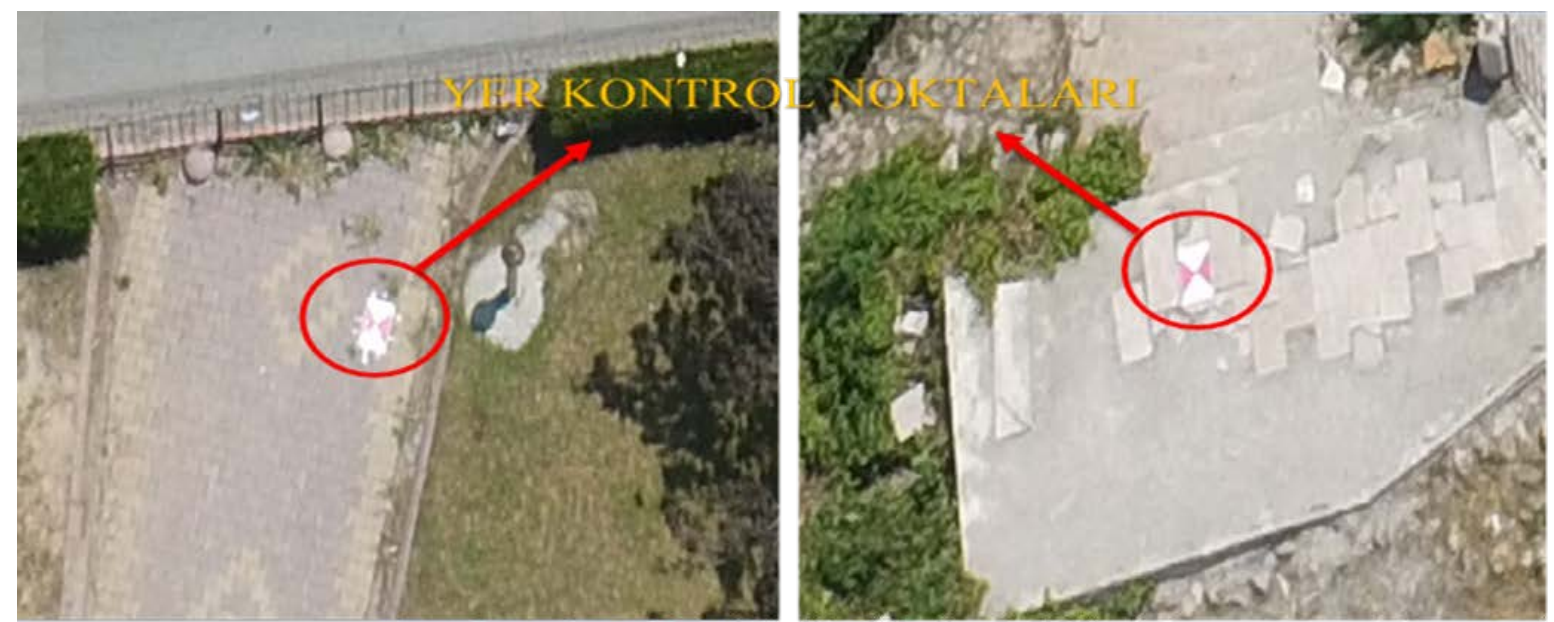

Şekil 4. Yer Kontrol noktalarının farklı fotoğraflarda işaretlenmesi (Referanslama)

$\mathrm{Bu}$ çalışmadan sonra insansız hava aracı işlemine geçilmiştir. Uçuşa başlamadan önce İHA kontrol edilmiştir ve ayrıca entegre edilen dijital kamera da kontrol edilmiştir. Daha sonra uçuş işlemine başlanmıştır. Taka'nın çatısı için fotoğraf çekilmiştir. Daha sonra Taka'nın çatı bölümü fotoğraf işlemi tamamlandiktan sonra yan cephe fotoğraf çekimi işlemine başlanmıştır.

Tablo 1. Yer Kontrol Noktaların Koordinat Tablosu

\begin{tabular}{|c|c|c|c|}
\hline Num. & $\mathrm{X}$ & $\mathrm{Y}$ & $\mathrm{Z}$ \\
\hline
\end{tabular}

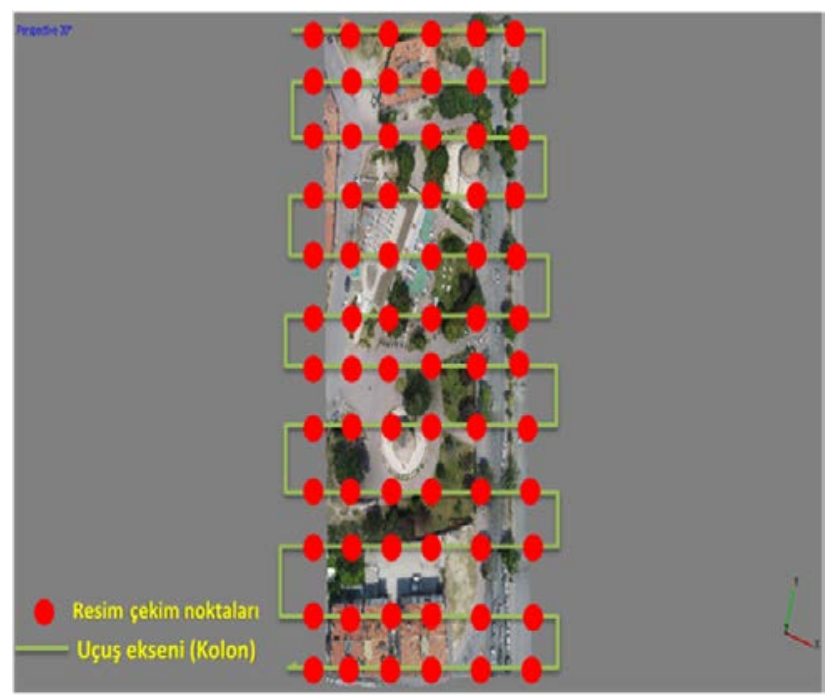

Şekil 3. Uçuş planı Resim çekin noktaları ve Uçuş ekseni 


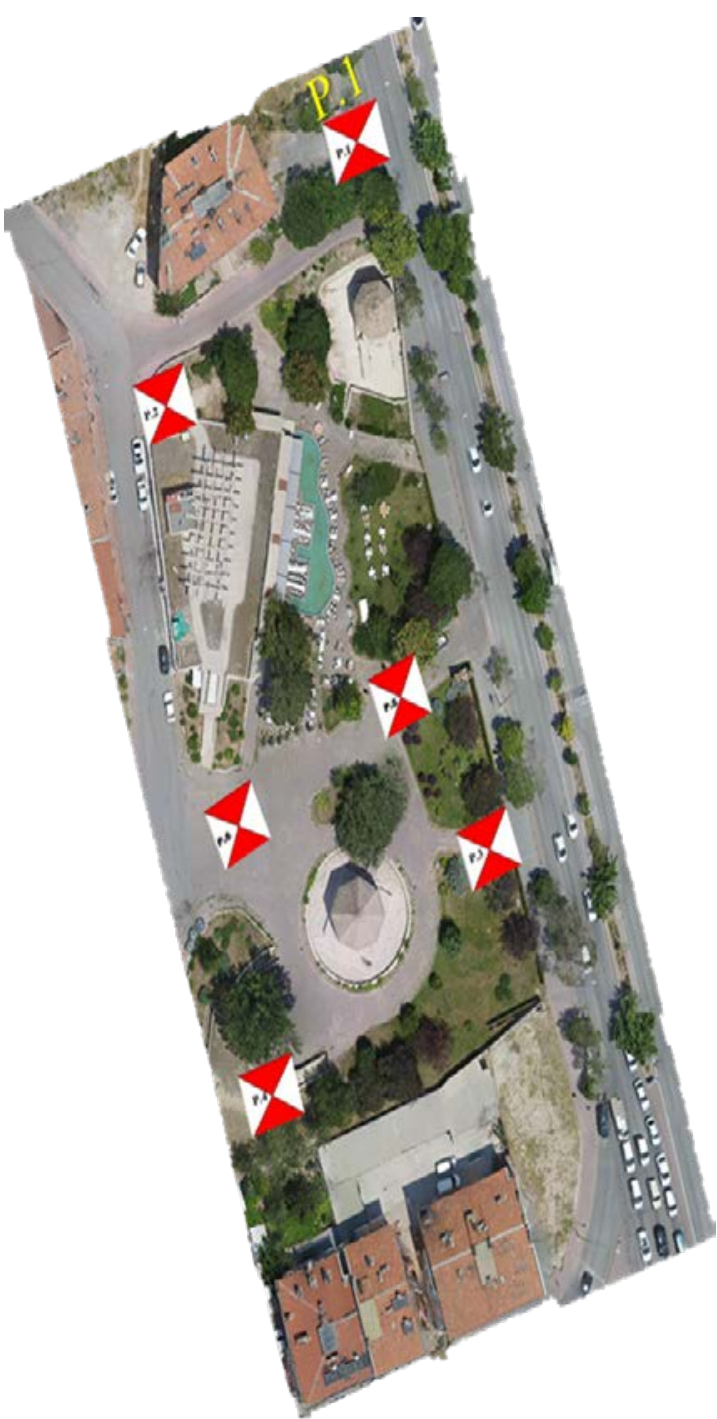

Şekil 5. Kalender Babanın ve Kesik Baş Türbesinin ortofotosu ve Yer kontrol notaları

\subsubsection{Ofis çalış̧ması}

Arazi çalışmasından elde edilen yer kontrol noktalarının koordinatlarını ve İnsansız Hava Aracı yardım ile çekilen fotoğraflar bilgisayara aktarılmıştır. Daha sonra koordinatlar "txt" formatı şekline kaydedilmiştir. Ayrıca kullanılacak fotoğraflar özel bir dosya şeklinde kaydedilmiştir. Ofis çalışmasında, Taka'nın 3 boyutlu modellenmesi için iki farklı program kullanılmıştır. "PIX4D ve AGISOFT" programı kullanılmıştır.

\subsubsection{Agisoft programı}

Agisoft Photoscan Pro. Yüksek çözünürlükte ortofoto ve son derece detayli DEM oluşturmasına olanak sağlar. Tam otomatik iş akışı, profesyonel fotogrametrik veri üretmek için bilgisayar ile havadan binlerce görüntüyü ișleyebilir. Yazılım JPEG, TİFF, PNG gibi bir dizi giriş formatlarını destekler. Bu kısım ofis çalışmasında Agisoft yazılımı kullanmıştır. Daha sonra arazi çalışmasından elde edilen fotoğraflar birkaç fotoğraf seçilmiştir. Seçilen fotoğraflar özel dosya şekilde kaydedilmiştir. Agisoft program yardım ile Kalender Baba ve Kesik Baş ayrı ayrı nokta bulutları üretilmiştir. Daha sonra ayrı ayrı kaplanmış katı modeli, kaplanmış 3B modelli ve ortofotoları da elde edilmiştir. Ayrıca İHA yardım ile çekilen fotoğraflar ve yerden dijital kamera yardım ile çekilen fotoğraflar birleşilerek Taka'nın 3B modeli ve ortofoto elde edilmiştir.

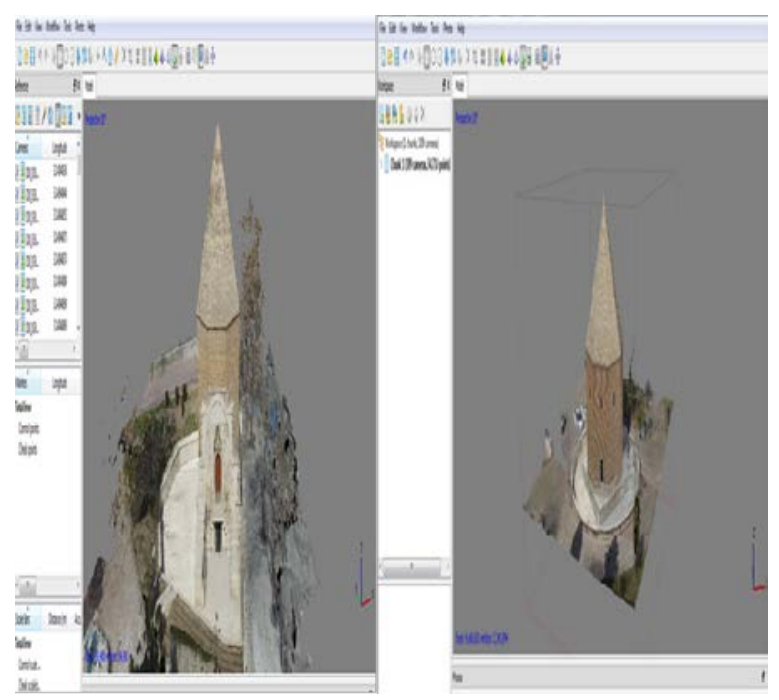

Şekil 6. Agisoft ile Kalender baba ve Kesik baş 3B modelinin son hali elde edilmiş görüntüsü

\subsubsection{PIX4D programı}

Yenilikçiliğiyle ve entegre CAD ve GIS düzenleme araçları ile tam bir haritalama ve modelleme çözümüdür. Yalnızca birkaç tıklama ile tam otomatik olarak yüksek doğrulukla ortomozaik, DSM ve nokta bulutu oluşturur. Sonuçlarınızı değerlendirebilir, düzenleyebilir ve yorumlayabilirsiniz. Mozaik Editor ile ortofotonuzu ve birleşim hatlarını düzenleme olanağ1 sunar. İstediğiniz kamera 
ve lensi kullanarak, hatta multi-spektral algılayıcılarla, hava fotoğraflarından veya eğik görüntülerden ortomozaik, DSM ve nokta bulutu oluşturur.

$\mathrm{Bu}$ kısım ofis çalışmasında PIX4D yazılımı kullanmıştır. Daha sonra arazi çalışmasından elde edilen fotoğraflar birkaç fotoğraf seçilmiştir. Ve seçilen fotoğraflar özel dosya şekilde kaydedilmiştir. PIX4D programı yardım ile Kalender baba-Kesik baş çatısının 3B modeli hem de Takanın yan kısmının 3B modeli elde edilmiştir.

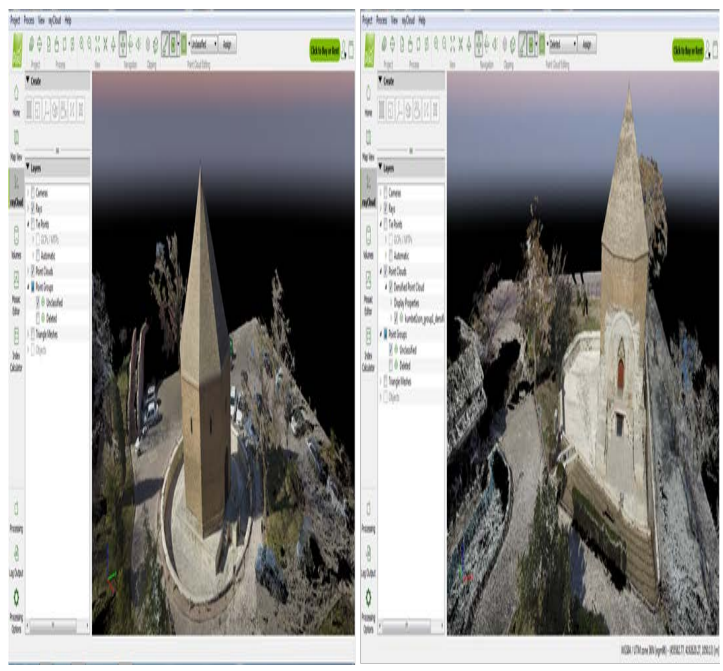

Şekil 7. Pix4D ile Kalender baba ve Kesik baş 3B modelinin son hali elde edilmiş görüntüsü

\section{SONUÇ VE ÖNERILER}

Tarihi eserleri ile zengin olan ülkemizde rölöve çalışmaları mimarlar tarafindan klasik yönteme göre yapılmaktadır. Fotogrametrik yöntem klasik yönteme göre önemli derecede bir avantaj sağlamaktadır. Tarihi ve kültürel eserlerin belgelenmesinde kullanıciya hem hız hem maliyet hem hassasiyet hem teknolojik olarak üstünlük sağlamaktadır.

Kalender baba-Kesik baş modellenmesi için İHA yöntemi kullanılmışıtır. Yersel Fotogrametri yöntemi Kültürel mirasın korunması için ve üç boyutlu modellenmesi için çok uzun zamandır kullanmaktadır. Fotogrametrik yöntemle tarihi eserler için model oluşturmada önemli aşamalar katedilmiş ve oldukça verimli sonuçlar elde edilmiştir. Kültürel miraslarımızın gerek çizgisel değerleri gerek doku kaplanmış şekilleri gerekse de video olarak animasyon halinde eseri her yönüyle incelemek mümkün olmaktadır.

Fakat 3B modelleme yapılacak tarihi eserlerin ve kültürel mirasın çatı gibi erişilemeyen noktalarının da fotoğraflanıp ölçülmesi gerekmektedir. Bu noktada yersel fotogrametri yetersiz kalmaktadır.

Bu çalışmada son yıllarda birçok alanda kullanılmaya başlanan İHA 'ya başvurulmuştur. Çatının farklı açılardan fotoğrafları çekilip, yerden çekilen fotoğraflarla ortak koordinat sisteminde dengelenip birleştirilerek çatı çizimleri gerçekleştirilmiştir. Ulaşılamayan yerlere ait fotoğrafların elde edilmesi çalışmalarını başarıyla tamamlayan İHA'nın bu açığı kapattığı gözlemlenmiştir. Fakat yersel fotogrametri iç mekanlarda çalışması zor olabilmektedir.

Tarihi ve kültürel mirasın korunması ve sonraki nesillere aktarılması için yapılan dokümantasyonunda İHA'ları ile Yersel Fotogrametri tekniklerinin birlikte kullanılması, bu alanda yapılan işlere doğruluk, hız ve maliyet anlamında yeni bir soluk getirdiği görülmüştür. İHA ile Fotogrametrik teknikler kullanılarak üretilen 3 boyutlu modellerin, restorasyon projelerinde altlı olabilecek nitelikleri taşıdığ gözlenmiştir. Ayrıca bu modellerin İHA'lar yardımıyla fotogrametrik teknikler kullanılarak yapılması, fotoğraf çekme olanaklarını artması ve dolayısı ile dokümantasyonun daha kapsamlı ve gerçekçi olmasına olanak sağlamaktadır.

$\mathrm{Bu}$ çalışma sonucunda aşağıdaki bulgulara ulaşılmıştır;

- Bu çalışmada tarihi olarak çok önemli olan Kalender baba-Kesik baş için gerek fotogrametrik ölçüm tekniği gerekse de İHA kullanılmış ve sonuçta bu yöntem alternatif değil destekleyici birer yöntem olduğu ortaya koyulmuştur.

- Tarihi ve kültürel mirasin korunmasi ve sonraki nesillere aktarılması için yapılan çalışmada İHA ile Yersel Fotogrametri tekniklerinin birlikte kullanılması, bu alanda yapılan işlere 
doğruluk, hız ve maliyet anlamında yeni bir soluk getirdiği görülmüştür

- Bu anlamda Fotogrametrik tekniklerin İHA'lar yardımıyla farklı disiplinlere de hizmet edebileceği görülmüştür.

- Elde edilen nokta bulutu verileri birleştirilerek yapılara ait detaylı 3 boyutlu nokta bulutlar1 oluşturulabilmektedir.

- Dış mekanların 3B modellenmesi için yersel fotogrametri yöntemi daha fazla tercih edilmektedir.

- Tarihi eserlerin çatılarını modellenmesi için İHA'lar daha uygun görülmüştür.

- Eğer İHA'ile eserin tam tepesinden düşey olarak çekilirse yan yüzeylerin modellenmesi yapilamamaktadır. Dolayısıyla eğer ki tarihi eserin yan yüzleri de modellenecekse yersel çekimlere ihtiyaç vardır.

- Çekimler eğer uygun pozisyonda yapılmaz ise özellikle de GPS'si olmayan İHA'ile yapıldığ zaman resim sirasında resimler ardıșık (arka arkaya) değilse modelleme yapılamamaktadır.

- İHA'ile çekim yaptığımız saat önemlidir, hafif bulutlu havalarda ya da Güneş tepedeyken çekilmeli çünkü gölge modelin görülmesini engeller.

- Çekim esnasında çalış1lacak objenin etrafinda İnsan ve diğer objelerin olmaması lazım, 1ssız zamanlarda çekilmesi daha uygundur.

- Eğer ortofoto üretilecek ise tam yatay (paralel) çekim yapılmalı eğik çekim yapılmamalıdır, eğik çekim yapıldı̆̆ 1 zaman modellere bozukluk yapar. Ama tarihi eserlerde yan yüzeylerde çekilecek ise tavsiyemiz şudur önce yerden eserin etrafina dönerek çekilmeli sonra uçuş planında yukarıdan paralel çekime geçirmeli ikisi birlikte daha güzel modellenir.

- Kullanilan programlara göre İHA'ların bir sorunu proses dengeleme işlemi çok uzun sürmektedir.
- Bazı yazılımlar da çizim kabiliyeti yoktur, diğer yazılımlar ise standart çizim menülerin işlemleri yapilmamaktadır. $\mathrm{Bu}$ nedenle dengeleme işlemi yapıldıktan sonra Üç Boyutlu çizim kabiliyeti olan programlarda çizim yapılması öneridir.

- Sadece ortofoto üretilecek ise bu yazılımlar yeterlidir, ama çizim yapılacaksa yazılımların yeterli olmadığ1 görülmüştür.

\section{KAYNAKÇA}

AKTAŞ, İ. (2007). Türkiye İnsansız Hava Aracı Yol Haritası, Sanayii Müsteşarlığı. Uzmanlık Tezi, Ankara. .

ALTINTAŞ, P., ÇAK, T. , YASTIKLI, N. (2014). Yersel Fotogrametrinin Tersine Mühendislik Uygulamalarında Kullanımı Harita Mühendisliği Bölümü Yıldız Teknik Üniversitesi

ASRİ, I., ÇORUMLUOĞLU, Ö. (2014). Tarihi Yerleşim Alanlarinin Yersel Fotogrametri Yöntemi İle 3b Modellenmesi: SantaHarabeleri Örneği 5. Uzaktan AlgilamaCbs Sempozyumu (Uzal-Cbs 2014), . İstanbul. .

KARSLI, F. ((2015-2016) ). Fotogrametriye Giriş Harita Mühendisliği Bölümü Mühendislik Fakültesi KTÜ

KÖK, M., YAKAR, M. (2015). Tarihi Sultanhanı Kervansarayı'nın Dijital Fotogrametrik Yöntemle Röleve Ölçülerinin Hazırlanmas1 , Bitirme Ödevi Harita Mühendisliği Bölümü Selçuk Üniversitesi Mühendislik Fakültesi

KÖK, T. (2012). "İnsansız Hava Araçlarının Güvenli Kullanım için Spektrum ihtiyaçlarının belirlenmesi ile ilgili öneriler , Teknik Uzmanlık Tezi, İstanbul.".

PAKKAN, B., ERMIŞ, M. , (2010). "İnsansız Hava Araçlarının Genetik Algoritma Yöntemiyle Çoklu Hedeflere Planlanması, ." Havacilık ve Uzay Teknolojileri Dergisi, Cilt 4. 
ŞANOĞLU İ., Z. M., KARAUĞUZ G. (2013). "Photogrammetric Survey and 3D ModelingBof Ivriz Rock Relief in Late Hittite Era " Mediterranean Archaeology and Archaeometry, 13 (2):147-157.

TANRITANIR, E. (2013). "), FOTOGRAMETRI NEDİR " www.geomatikmuhendisligi.co info@geomatikmuhendisligi.com.

ULVI, A., YAKAR, M. (2015). Metrik Olmayan Dijital Kameraların Hava Fotogrametrisinde Yakın Resim Çalışmalarda(Yere Yakın Yüksekliklerde) Kullanılabilirliği Üzerine Bir Çalışma , Doktora Tezi Harita Mühendisliği Bölümü Selçuk Üniversitesi

Yılmaz, H. M., Karabörk, H. , Yakar, M. (2000). "), Yersel Fotogrametrinin Kullanım Alanları " Niğde Üniversitesi Mühendislik Bilimleri Dergisi, Cilt 4 Say1 1. 